\title{
Roles of Intracellular cAMP and Protein Kinase A in the Actions of Dopamine and Neurotensin on Midbrain Dopamine Neurons
}

\author{
Wei-Xing Shia and Benjamin S. Bunney \\ Departments of Psychiatry and Pharmacology, Yale University School of Medicine, New Haven, Connecticut 06510
}

The role of intracellular CAMP and protein kinase $A$ in dopamine-induced inhibition of dopamine neurons and the attenuation of this inhibition by neurotensin were studied in rat midbrain slices. Spontaneous activity of dopamine cells was recorded extracellularly from both the ventral tegmental area and the substantia nigra. Perfusion of the slices with 8-bromo-cAMP and forskolin significantly attenuated dopamine-induced inhibition, but neither blocked the inhibition completely. Neither SQ22536, an inhibitor of adenylate cyclase, nor $\mathrm{H8}$, an inhibitor of protein kinase A, mimicked the inhibitory effect of dopamine on dopamine neurons, although they potentiated dopamine's effect. These results indicate that dopamine-induced inhibition of dopamine neurons can be affected by intracellular cAMP levels, but is unlikely to be mediated solely by inhibition of adenylate cyclase.

The similarities between the effects of neurotensin and those of 8-bromo-cAMP and forskolin suggest that intracellular CAMP may be involved in the actions of neurotensin. This suggestion is supported by our findings that isobutylmethylxanthine (an inhibitor of phosphodiesterases) potentiated the effect of neurotensin and SQ22536 and H8 antagonized it. Phorbol-12,13-dibutyrate (an activator of protein kinase C) did not mimic the effect of neurotensin, and $\mathrm{H7}$ (an inhibitor of protein kinase $C$ ) did not reduce the effect, suggesting that protein kinase $C$ is unlikely to be involved in the modulatory effect of neurotensin.

Activation of dopamine (DA) D1 receptors leads to an increase in the production of intracellular CAMP, whereas stimulation of $\mathrm{D} 2$ receptors decreases the activity of adenylate cyclase. DA receptors on DA cells in both the ventral tegmental area (VTA) and the substantia nigra (SN) have the characteristics of a D2 receptor (White and Wang, 1984; Lacey et al., 1987). Activation of these receptors not only produces an inhibition of the electrical activity, but also induces a decrease in cAMP production (Memo et al., 1987). Pertussis toxin, which inactivates $G_{i}$ protein and blocks the inhibitory effect on cAMP production induced by activation of the receptors negatively linked with adenylate cyclase, also blocks the inhibition of firing rate of DA

\footnotetext{
Received Aug. 26, 1991; revised Jan. 16, 1992; accepted Jan. 22, 1992.

We thank Chen-Lun Pun for technical assistance. This work was supported by U.S. Public Health Service Grants MH28849 and MH25642, by the Stanley Foundation for Research on Serious Mental Diseases, and by the Abraham Ribicoff Research Facilities at the Connecticut Mental Health Center, State of Connecticut.

Correspondence should be addressed to B. S. Bunney, M.D., Departments of Psychiatry and Pharmacology, Yale University School of Medicine, 25 Park Street, New Haven, CT 06510.

a Present address: Department of Psychiatry, Columbia University, 722 West 168th Street, Box 62, New York, NY 10032.

Copyright (C) 1992 Society for Neuroscience $0270-6474 / 92 / 122433-06 \$ 05.00 / 0$
}

neurons induced by DA (Innis and Aghajanian, 1987). These observations suggest that intracellular cAMP may play an important role in DA-induced inhibition of DA neurons. In this study, we begin to examine whether the inhibition of DA neuron activity induced by DA is mediated or regulated by a decrease in intracellular cAMP level. In the same study, we also examined the possibility that intracellular cAMP may be involved in the interaction between neurotensin (NT) and DA on DA cells.

Central NT systems are anatomically closely related to midbrain DA systems. Central administration of NT produces many pharmacological effects resembling those produced by neuroleptics. We have previously shown that application of NT selectively attenuates DA-induced inhibition of midbrain DA neurons (Shi and Bunney, 1991a,b). Although formation of an NT-DA complex has been suggested as a mechanism for some of the neuroleptic-like effects of NT (Adachi et al., 1990), our previous studies have suggested that the effects of NT on the activity of DA neurons are most likely mediated by activation of NT receptors (Shi and Bunney, 1991b). Results from receptor binding studies (Nemeroff et al., 1983; Sarrieau et al., 1985; Kanba et al., 1986; Moyse et al., 1987) indicate that NT, rather than competing with DA for the same receptor, acts on separate binding sites that are specific for NT. It is possible that the binding sites for both NT and DA are separate but within one receptor protein complex, as has been proposed for the receptors for glycine and glutamate, and benzodiazepines and GABA. Activation of the NT binding site may lead to a configuration change of the receptor protein complex and result in a decrease in the affinity of the DA binding site. Such a process may not require an intermediate, that is, a second messenger system. On the other hand, it is becoming clearer that many neurotransmitters or neuromodulators produce their physiological effects through their actions on the intracellular second messenger systems that are directly or indirectly coupled with the receptors on the cell surface. Changes in second messenger systems provide another means by which different neurotransmitters acting on the same cell interact with each other. The experimental results described here indicate that NT may act through an intracellular cAMP system to modulate DA-induced inhibition of DA cells.

Some of these results have been reported previously (Shi and Bunney, 1988, 1989).

\section{Materials and Methods}

The techniques used for these experiments are similar to those described previously (Shi and Bunney, 1990, 1991b). Male Sprague-Dawley albino rats, weighing between 80 and $150 \mathrm{gm}$, were used. They were anesthetized using either the inhalation anesthetic halothane or by intraperitoneal chloral hydrate $(400 \mathrm{mg} / \mathrm{kg})$, and the brain was removed from the skull. A block of tissue containing the mesencephalon was prepared and cut into $400 \mu \mathrm{m}$ sagittal or coronal slices using a Stoelting 

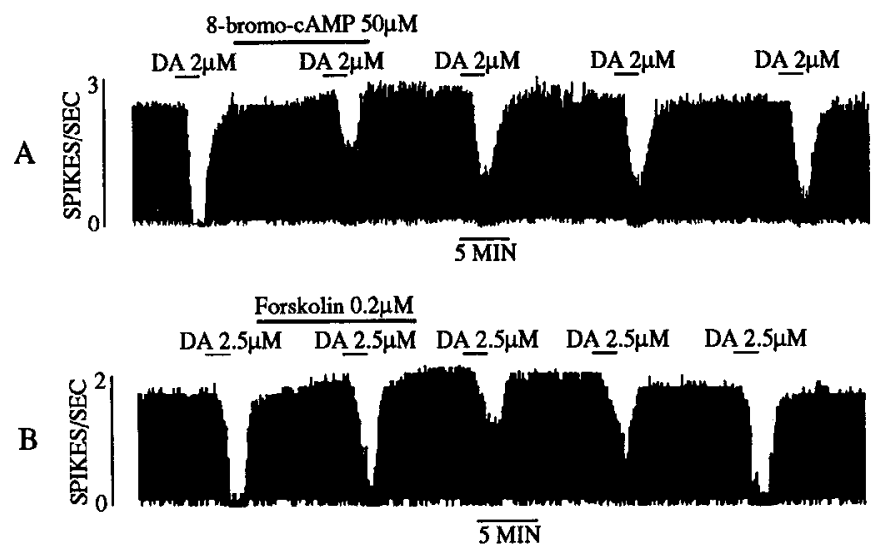

Figure 1. Typical histograms showing the effects of 8-bromo-cAMP and forskolin on DA-induced inhibition of midbrain DA neurons. $A$, Application of DA $(2 \mu \mathrm{M})$ caused a total inhibition of firing in this cell. During the perfusion of 8-bromo-cAMP $(50 \mu \mathrm{M})$, however, the same application of DA produced only $44 \%$ inhibition. This modulatory effect of 8-bromo-cAMP was long lasting and was accompanied by a small and delayed excitation $(15 \%)$. The inhibition of DA slowly recovered after 8-bromo-cAMP was removed from the superfusion medium. However, it still had not reached its control value after a $40 \mathrm{~min}$ washout period, though by this time the basal firing rate of the cell had returned to the level observed before the application of 8-bromo-cAMP. $B$, In a different cell, DA at $2.5 \mu \mathrm{M}$ produced over a $90 \%$ inhibition of basal firing rate. Perfusion of the slice with forskolin $(0.5 \mu \mathrm{M})$ reduced this inhibition to $43 \%$. As seen with 8-bromo-cAMP, forskolin also caused a slight increase in basal firing rate $(13 \%)$. In this and following figures, bars represent the duration of drug perfusion.

tissue chopper. A single slice containing either the VTA or the SN was transferred to the recording chamber, in which it rested on a piece of tissue paper. The slice was initially maintained in a medium/gas interface for about 15-30 min, and then immersed in a continuously flowing incubating medium throughout the rest of the experiment. Data were collected after $1.5-2 \mathrm{hr}$ incubation. The perfusion medium contained (in $\mathrm{mm}$ ) $\mathrm{NaCl}, 124 ; \mathrm{KCl}, 4 ; \mathrm{CaCl}_{2}, 2.4 ; \mathrm{MgSO}_{4}, 1.3 ; \mathrm{NaH}_{2} \mathrm{PO}_{4}, 1.2$; $\mathrm{NaHCO}_{3}, 25$; and glucose, 10; and was saturated with $95 \% \mathrm{O}, 5 \% \mathrm{CO}$. A constant medium perfusion rate of about $0.5 \mathrm{ml} / \mathrm{min}$ was provided by a homemade pulse-free medium supply system using a peristaltic pump (Shi and Bunney, 1990). The temperature of the perfusion medium within the recording chamber was kept constant at about $34^{\circ} \mathrm{C}$.

Action potentials of spontaneously active DA cells were recorded extracellularly by conventional techniques (Bunney et al., 1973; Shi and Bunney, 1991b). Electrodes were filled with perfusion medium. DA cells were identified by (1) their anatomical location within the SN or the VTA, (2) an inhibitory response to DA application, and (3) well-established electrophysiological criteria (Bunney et al., 1973; Grace and Bunney, 1983). Cells exhibited long-duration (2-3 msec) biphasic action potentials. Single spikes frequently exhibited a distinct initial segment/ somatodendritic break in the early phase of the action potential. The majority of cells recorded were located in the anterior part of the VTA and anteriomedial part of the $\mathrm{SN}$. There was, however, no significant difference in results obtained from cells with different locations. Unit activity was converted to an integrated histogram by a rate-averaging computer and displayed as spikes/ $10 \mathrm{sec}$ on a chart recorder. Numerical data are presented as means + SFM

SQ22536 was obtained from Squibb. $\mathrm{H} 7$ and $\mathrm{H} 8$ were purchased from Seikagaku America Inc. (St. Petersburg, FL). All other drugs were purchased from Sigma. Drugs were delivered to the slices via bath perfusate and washed out by returning the slices to the original perfusion medium.

\section{Results}

Modulation of $D A$-induced inhibition by intracellular $C A M P$ and protein kinase $A$

As reported previously (Shi and Bunney, 1991b), bath application of DA (1-100 $\mu \mathrm{M})$ dose-dependently inhibited the spon- taneous activity of DA neurons. Co-administration of the D2 selective antagonist sulpiride $(2 \mu \mathrm{M})$ totally blocked this unhibitory effect of DA (not shown). To determine whether DA suppresses DA cell firing by inhibition of adenylate cyclase, thereby lowering intracellular cAMP levels, we treated DA cells with 8-bromo-cAMP. 8-Bromo-cAMP is a membrane permeable analog of cAMP and has been shown to mimic the action of direct intracellular injection of cAMP (e.g., Madison and Nicoll, 1986). If DA-induced firing inhibition is mediated by an inhibition of adenylate cyclase, 8-bromo-cAMP acting beyond the step of adenylate cyclase should block the effect of DA. We found that DA-induced inhibition, though greatly attenuated, persisted during 8-bromo-cAMP even at concentrations (up to $1 \mathrm{mM}$ ) that significantly increased firing rate above baseline (not shown). The partial antagonism of DA-induced inhibition by 8 -bromocAMP indicated that DA may act partially via inhibition of adenylate cyclase. To ensure that the attenuation of DA-induced inhibition by 8 -bromo-cAMP was not secondary to the excitatory effect of 8-bromo-cAMP, we treated DA cells with low concentrations of 8-bromo-cAMP (50-200 $\mu \mathrm{M} ; n=17)$. At these concentrations, 8-bromo-cAMP produced either no effect or a small increase in firing rate. DA-induced inhibition was, however, still significantly reduced (from $93.0 \pm 2.4 \%$ to $45.0 \pm$ $4.8 \%$ of baseline; Fig. $1 A$ ).

To confirm that 8-bromo-cAMP produced its effects by mimicking intracellular cAMP to activate protein kinase $\mathrm{A}$, we used forskolin, a direct activator of adenylate cyclase, and H8 ( $\mathrm{N}$-[2(methylamino)ethyl]-5-isoquinolinesulfonamide), a potent inhibitor of protein kinase A (Hidaka et al., 1984). Application of forskolin was found to mimic the effects produced by 8-bromocAMP. In 11 cells, forskolin (0.1-0.5 $\mu \mathrm{M})$ significantly reduced the inhibition of DA cells induced by DA (from $87.6 \pm 3.9 \%$ to $55.1 \pm 4.4 \%$ of baseline; Fig. $1 B$ ). At higher concentrations $(0.5-5 \mu \mathrm{M})$ it also increased the firing rate of the cell. The protein kinase A inhibitor $\mathrm{H} 8$ (20-30 min, 80-100 $\mu \mathrm{M}$ ) effectively reversed 8-bromo-cAMP-induced attenuation of DA-inhibition (from $56.3 \pm 6.1 \%$ to $3.8 \pm 8.2 \%$ attenuation; $n=5$; see Fig. $3 B$ ). The increase in basal firing rate by 8 -bromo-cAMP was, however, not significantly affected by the same treatment of $\mathrm{H} 8$, suggesting that 8 -bromo-cAMP may produce this effect via a mechanism independent of protein kinase $A$.

If, as suggested by the above results, activation of D2 autorcceptor suppresses DA cell firing partially via an inhibition of adenylate cyclase and protein kinase $A$, then the direct inhibitors of these enzymes should mimic the effect of DA and inhibit the activity of DA neurons. To study this hypothesis, we treated DA cells with SQ22536, an analog of adenosine that has been shown to inhibit the activity of adenylate cyclase (Harris et al., 1979; Madison and Nicoll, 1986). In contrast to the prediction, perfusion of SQ22536 (10-50 $\mu \mathrm{M})$ for $30 \mathrm{~min}$ or longer had no effect on basal activity of the cell (see Fig. $2 B$ ), though the same concentrations of SQ22536 slightly potentiated DA-induced inhibition of cell activity and markedly attenuated the modulatory effect of NT (see following section). Similarly, slice perfusion with $\mathrm{H} 8$ (50 $\mu \mathrm{M}$ to $2 \mathrm{mM} ; n=17)$ for up to $30 \mathrm{~min}$ did not produce any inhibition of the spontaneous activity of DA cells, though the same treatment slightly potentiated DA-induced firing inhibition and effectively reversed the effect of 8-bromocAMP (sce Fig. 3). These results suggest that DA-induccd inhibition of DA neurons is unlikely to be mediated solely by inhibition of adenylate cyclase. However, these and the above results with 8-bromo-cAMP and forskolin support the notion 

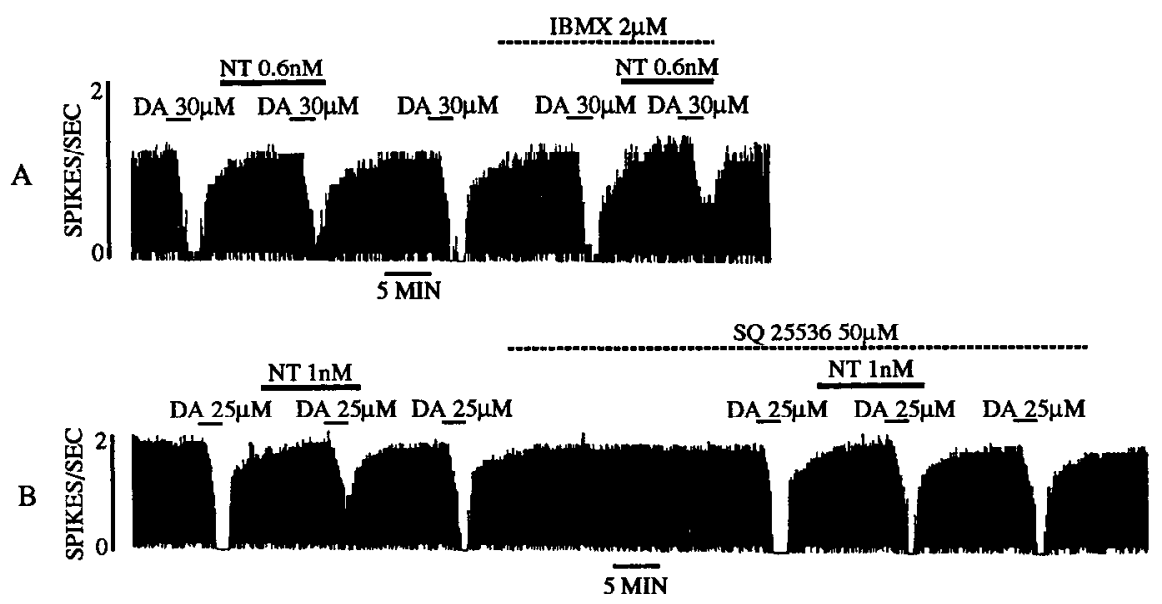

Figure 2. Representative histograms showing the effects of IBMX and SQ22536 on NT-induced modulation of DA cell activity. $A$, NT at $0.6 \mathrm{nM}$ slightly attenuated the inhibition induced by DA $(30 \mu \mathrm{M})$ in this cell. Application of IBMX $(2 \mu \mathrm{M})$ alone also did not significantly modify the inhibitory effect of DA. When NT and IBMX were co-administered, however, the inhibition induced by DA was markedly attenuated $(50 \%)$. $B$, In a separate cell, application of DA $(25 \mu \mathrm{M})$ totally inhibited the firing of the cell. In the presence of NT ( $1 \mathrm{nM})$, the same application of DA caused only $50 \%$ inhibition. This modulatory effect of NT was greatly diminished by the treatment of the slice with SQ22536 $(50 \mu \mathrm{M})$. Note that, unlike DA, SQ22536 had no effect on the basal firing rate. that the ability of DA to inhibit DA cells can be modulated by intracellular cAMP and protein kinase $\mathrm{A}$.

\section{Involvement of intracellular cAMP and protein kinase $A$ in the modulatory effect of $N T$}

As reported previously (Shi and Bunney, 1991b), concomitant administration of NT markedly attenuated DA-induced inhibition of DA cells (Figs. 2-4). NT at concentrations higher than $10 \mathrm{~nm}$ also increased firing rate of the cell (Shi and Bunney, $199 \mathrm{lb}$ ). 'These effects of N'I were very similar to those produced by 8 -bromo-cAMP and forskolin, suggesting a possible involvement of intracellular cAMP and protein kinase $A$ in the action of NT. To examine this possibility, we applied IBMX (isobutylmethylxanthine), an inhibitor of phosphodiesterases, to DA cells. If the effects of NT are mediated through an increase in intracellular cAMP, IBMX by preventing cAMP from being degraded should potentiate the effects of NT. At concentrations of 2-5 $\mu \mathrm{M}$, IBMX by itself either had no effect or slightly increased the firing rate of DA cells. DA-induced inhibition was slightly attenuated. When co-administered with NT, however, IBMX significantly potentiated the modulatory effect of NT (from $21.0 \pm 3.0 \%$ to $48.5 \pm 1.7 \%$ attenuation; $n=5$; Fig. $2 A$ ).

We further tested our hypothesis using the adenylate cyclase inhibitor SQ22536 and the protein kinase A inhibitor H8. Bath application of SQ22536 (10-50 $\mu \mathrm{M})$ for $30 \mathrm{~min}$ or longer markedly attenuated the modulatory effect of NT (from $45.6 \pm 3.3 \%$ to $14.6 \pm 7.4 \%$ attenuation; $n=5$; Fig. $2 B$ ). At the same time, SQ22536 also caused a small potentiation of DA-induced inhibition. NT-induced excitation was found to bc largely unaffected, implying that the excitatory effect of NT may not be mediated by adenylate cyclase. Similarly, treatment with $\mathrm{H} 8$ $(80 \mu \mathrm{M}, 30 \mathrm{~min})$ effectively reversed NT-induced attenuation of DA-inhibition in all cells studied (from $49.0 \pm 3.4 \%$ to $3.2 \pm$ $5.3 \%$ attenuation; $n=8$; Fig. $3 A$ ). Shorter-term $(10 \mathrm{~min})$ treat-
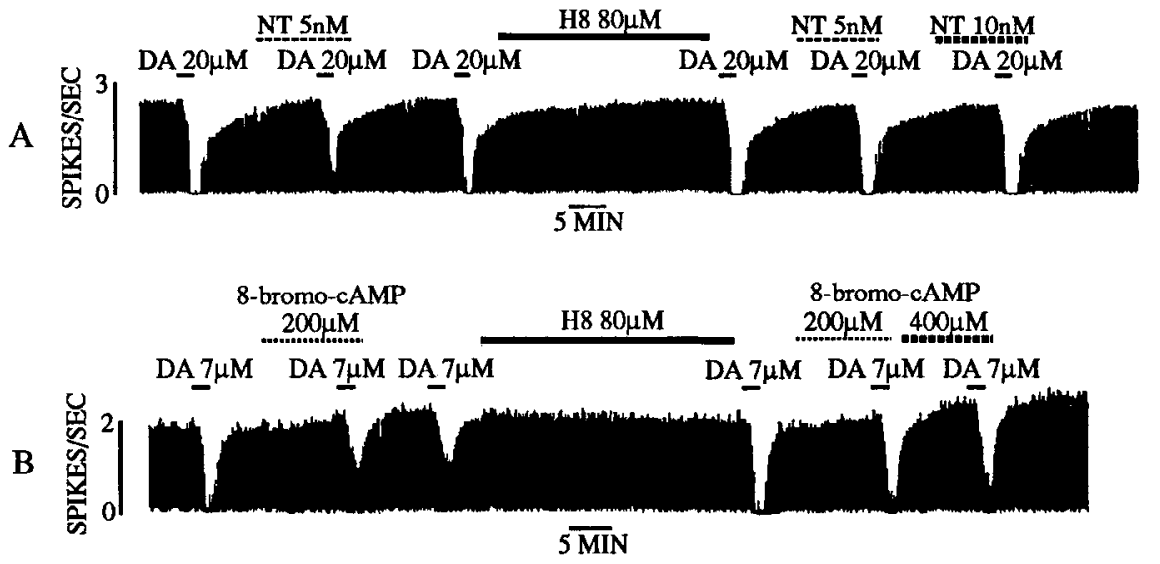

Figure 3. Typical histograms showing the reversal of the modulatory effects of 8 -bromo-cAMP and NT by H8. $A$, Perfusion of DA (20 $\mu \mathrm{M}$ ) in the control condition caused a total cessation of the spontaneous firing of the cell. This inhibition was significantly attenuated by co-administration of NT (5 nM). After a 30 min treatment with $\mathrm{H} 8(80 \mu \mathrm{M})$, however, the modulatory effect of NT on DA-induced inhibition vanished. Doubling the concentration of NT to $10 \mathrm{~nm}$ still did not produce any attenuation of DA inhibition. Note that $\mathrm{H} 8$ itself had no effect on basal firing rate of the cell. $B$, In a separate cell, application of DA at $7 \mu \mathrm{M}$ produced a more than $90 \%$ inhibition of the firing. This inhibition was reduced to about $50 \%$ by concomitant administration of 8-bromo-cAMP $(0.2 \mathrm{mM})$. This treatment of 8-bromo-cAMP also caused a small increase in basal firing rate $(16 \%)$. The cell was then treated with $\mathrm{H} 8(80 \mu \mathrm{M})$ for $30 \mathrm{~min}$. Following the treatment, the same dose of 8 -bromo-cAMP that before had significantly attenuated DA inhibition had little effect. Doubling the dose of 8 -bromo-cAMP, though causing more excitation, still was not as effective in attenuating the inhibitory effect of DA as the lower dose administered before $\mathrm{H} 8$. 


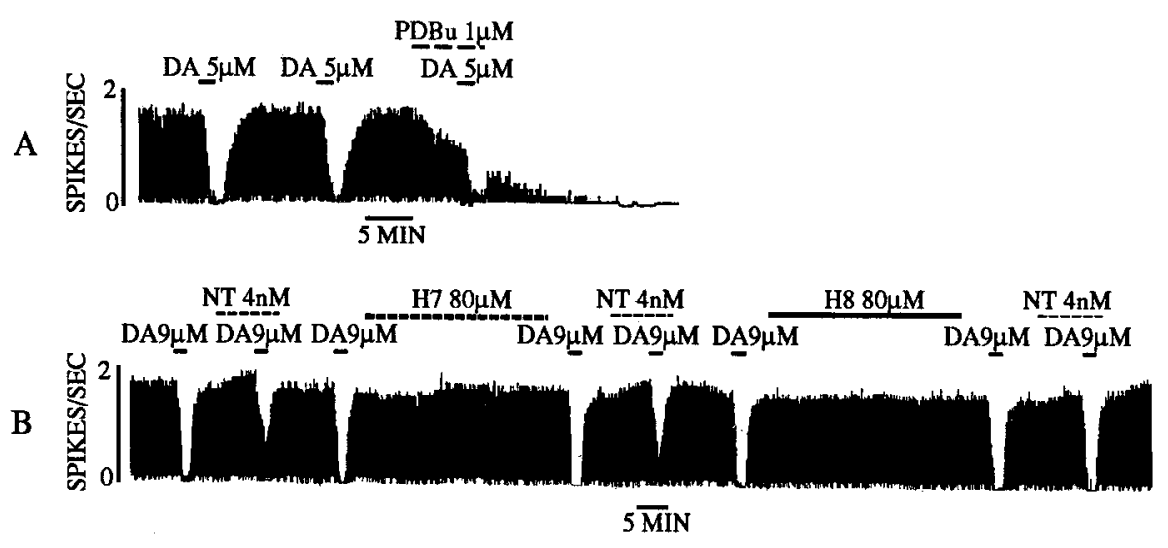

Figure 4. Typical histograms showing the effect of PDBu and $\mathrm{H} 7$ on midbrain DA neurons. $A$, Application of PDBu (1 $\mu \mathrm{M})$ in this cell totally inhibited the firing of the cell. Unlike the depolarization inactivation induced by glutamate or chronic treatment with neuroleptics, the inhibition induced by PDBu developed slowly without any sign of excitation. As the firing rate decreased, the shape and the size of the action potentials did not change (not shown). $B$, In a different cell, the effect of $\mathrm{H} 7$ on NT-induced modulatory effects was compared with that of $\mathrm{H} 8$. Treatment of the cell with $\mathrm{H} 7(80 \mu \mathrm{M}, 30 \mathrm{~min})$ in a manner identical to that used for $\mathrm{H} 8$ did not significantly attenuate the modulatory effect of NT (4 nM). However, $\mathrm{H} 8$ reversed the attenuation of DA $(9 \mu \mathrm{M})$ inhibition induced by NT.

ment with $\mathrm{H} 8(80-200 \mu \mathrm{M})$ was found to be less effective. In some cases, H8 potentiated the inhibition induced by DA (e.g., Fig. 3).

To determine whether protein kinase $\mathrm{C}$ is also involved in the action of NT, we treated the cell with PDBu (phorbol-12,13dibutyrate). In contrast to NT and 8-bromo-cAMP, PDBu (20 $\mathrm{nM}$ to $1 \mu \mathrm{M})$ in all five cells tested consistently caused an inhibition of DA cell firing rate (Fig. $4 A$ ). The inhibition induced by PDBu often had a slow onset and gradually reached its maximum effect (100\% inhibition of firing) without any sign of excitation. No significant change in either the amplitude or the duration of the action potentials was observed during this process. After spontaneous activity stopped, a full-size action potential could still be evoked by touching the cell with the recording electrode. Based upon these observations, it was concluded that the inhibition induced by PDBu was unlikely to be due to depolarization inactivation. The inhibition of the spontaneous activity induced by PDBu was dose dependent and very long lasting ( $>30 \mathrm{~min}$ ).

To confirm further that protein kinase $\mathrm{C}$ is not involved in the modulatory effect of $\mathrm{NT}$ and that $\mathrm{H} 8$ produced its reversing effect not by inhibiting protein kinase $\mathrm{C}$, we exposed the cell to $\mathrm{H} 7$ [1-(5-isoquinolinylsulfonyl)-2-methylpiperazine]. $\mathrm{H} 7$ is an analog of $\mathrm{H} 8$ and is more potent than $\mathrm{H} 8$ in inhibiting protein kinase $\mathrm{C}$ (Hidaka et al., 1984). We found that $\mathrm{H} 7$ was much less effective than $\mathrm{H} 8$ in diminishing the modulatory effect of NT on DA-induced inhibition of DA cells, though the identical treatment regimen was used $(80 \mu \mathrm{M}, 30 \mathrm{~min} ; n=5)$. In the same cells where treatment with $\mathrm{H} 7$ was shown ineffective, $\mathrm{H} 8$ produced its usual antagonism of the effect induced by NT (Fig. $4 B)$.

\section{Discussion}

Many hormones and neurotransmitters have been shown to inhibit adenylate cyclase activity via GTP-binding protein $\left(\mathrm{G}_{i}\right)$. In addition to the attenuation of CAMP production, occupancy of the receptors linked to inhibition of adenylate cyclase also produces many other biochemical and electrophysiological changes of the cell, including suppression of hormone or neurotransmitter release, activation of $\mathrm{K}^{+}$conductances, and in- hibition of voltage-sensitive $\mathrm{Ca}^{2+}$ channels. Though in some cases these additional changes may be the result of the decreased production of intracellular CAMP, in many other cases it seems that receptors linked to inhibition of adenylate cyclase do not operate solely by decreasing cAMP production (see review by Limbird, 1988). Our results in the present study suggest that this may be the case for D2 autoreceptor-mediated inhibition of DA cell activity. Thus, if DA inhibition is solely mediated by a decrease in the activity of adenylate cyclase, thereby lowering the level of intracellular cAMP, 8-bromo-cAMP, acting beyond the step of adenylate cyclase, should antagonize the inhibition of DA. In this study, however, 8-bromo-cAMP was found only to attenuate it; full blockade of DA inhibition was not observed. In addition, SQ22536, which inhibits adenylate cyclase, was unable to mimic the inhibitory effect of DA, though at the same concentrations it potentiated DA inhibition and reduced the modulatory effect of NT. Similar results were obtained with $\mathrm{H} 8$, which, though effectively reversing the attenuation of DA inhibition by both 8-bromo-cAMP and NT, had no effect on the basal firing rate of DA cells.

Although the above discussion suggests that inhibition of adenylate cyclase alone is unlikely to be the mechanism by which DA produces its inhibitory effect on DA cells, our results support the hypothesis that the inhibitory effect of DA on DA neurons can be regulated by intracellular cAMP levels. Activation of adenylate cyclase or protein kinase $A$ by forskolin and 8-bromocAMP, respectively, attenuated the inhibition induced by DA, whereas inhibition of the same enzymes by SQ22536 and H8 potentiated the effect of DA. Recent studies by Elazar and Fuchs (1991) indicate that an increase in the level of intracellular cAMP and the activity of protein kinase A leads to a direct phosphorylation of the D2 receptor. Such phosphorylated D2 receptors exhibit much lower affinities to D2 agonists compared to nonphosphorylated ones. It is unknown whether protein kinase A also phosphorylates other proteins such as G-proteins and ion channels that are coupled with $\mathrm{D} 2$ receptors.

Knowing that intracellular cAMP can modulate the effect of DA and that agents increasing the activity of intracellular cAMP produce effects similar to those of NT, we further examined the possibility that NT may produce its effect via an increase in intracellular cAMP levels. First, the effect of NT was measured 
in the presence and absence of IBMX. If NT acts through cAMP systems, IBMX, which prevents intracellularly produced cAMP from being metabolized, should potentiate the effect of NT. Indeed, co-application of IBMX potentiated the ability of NT to diminish the inhibition induced by DA. Second, the effect of NT was determined while adenylate cyclase was inhibited by SQ22536. Consistent with the hypothesis, SQ22536 markedly reduced the effect of NT. Finally, the protein kinase A inhibitor H8 fully reversed the modulatory effect of NT. In supporting our findings, Kalivas and colleagues [Kalivas (1992)] have recently found that $\mathrm{H} 8$ blocks intra-VTA NT-induced behavioral effects in the rat. The results with $\mathrm{H} 8$ indicate that an increase in protein phosphorylation mediated by protein kinase $\mathrm{A}$ is involved in the action of NT. As has been mentioned above (Flazar and Fuchs, 1991), direct phosphorylation of D2 receptor protein by protein kinase A does mimic the effect of NT, that is, reducing the affinity of the D2 receptor for its agonist but not the antagonist (Agnati et al., 1983; Von Euler and Fuxe, 1987). It remains to be determined, however, whether NT receptors are directly coupled to adenylate cyclase or indirectly by acting on other messenger systems that converge on adenylate cyclase and protein kinase A. Since inhibition of adenylate cyclase and protein kinase A by SQ22536 and $\mathrm{H} 8$ can reverse the modulatory effect of NT, it is unlikely that NT acts downstream from protein kinase $A$.

Inhibition of cAMP- and protein kinase A-mediated cellular processes by $\mathrm{H} 8$ has been reported in many studies (e.g., Anwer et al., 1990; Boulis and Davis, 1990; Funase, 1990; Tokimasa and Akasu, 1990; Watanabe and Funase, 1991). Studies in a broken cell preparation by Hidaka et al. (1984), however, indicated that $\mathrm{H} 8$ also inhibits several other protein kinases including protein kinase $\mathrm{C}$. A possible involvement of protein kinase $\mathrm{C}$ in the actions of NT was also suggested by Geodert et al. (1984) in studies of rat brain slices. Incubation of NT $(1 \mu \mathrm{M})$ was found to increase the hydrolysis of inositol phospholipids in slices taken from several areas of brain, including the midbrain. It is known that hydrolysis of inositol phospholipids generates two products, diacylglycerol and inositol 1,4,5-triphosphate. Each of them has independent roles as second messengers. Inositol 1,4,5-triphosphate stimulates the release of $\mathrm{Ca}^{2+}$ from intracellular membrane stores, whereas diacylglycerol activates protein kinase $\mathrm{C}$. To determine if protein kinase $\mathrm{C}$ is involved in NT's action, we treated DA cells with $\mathrm{H7}$, a more potent protein kinase $\mathrm{C}$ inhibitor. If the effect of NT is mediated by protein kinase $\mathrm{C}$ and $\mathrm{H} 8$ blocks the effect of NT by inhibiting this enzyme, $\mathrm{H} 7$ should be more effective than $\mathrm{H} 8$ in reversing the effect of NT. Contrary to this prediction, $\mathrm{H} 7$ was found to be much less effective than $\mathrm{H} 8$ in antagonizing the modulatory effect of NT. These results suggest that the reversal of the NTinduced effect by $\mathrm{H} 8$ is not due to its effect on protein kinase $\mathrm{C}$ and that the ineffectiveness of $\mathrm{H} 7$ in antagonizing the effect of NT is probably due to its inability to inhibit protein kinase $A$ at the concentrations used in the present study. This suggestion is supported by other studies in whole-cell preparations in which $\mathrm{H} 8$ was found to inhibit protein kinase A-mediated processes selectively without a significant effect on those processes mediated by protein kinase C (e.g., Mitsuhashi and Payan, 1988; Morita et al., 1988; Linden and Routtenberg, 1989; Bankey et al., 1990; Moraru et al., 1990; Teitelbaum, 1990; Yomato et al., 1990). Conversely, $\mathrm{H} 7$ inhibited the protein kinase $\mathrm{C}-\mathrm{me}-$ diatcd cellular activitics without much influence on those mediated by protein kinase A (e.g., Conn et al., 1989; Poueymirou and Schultz, 1989; Anwer et al., 1990; Boulis and Davis, 1990; Teitelbaum, 1990; Manejwala et al., 1991). The inability of $\mathrm{PDBu}$ to mimic the effect of NT in our preparation further supports the conclusion that protein kinase $\mathrm{C}$ is unlikely to be involved in the modulatory effect of NT on DA cells. Our data, however, did not rule out the possibility that protein kinase $C$ may be involved in other actions of NT. We have previously shown that NT produced several effects at different concentrations (Shi and Bunney, 1991b). At low concentrations (0.2-10 $\mathrm{nM})$, NT attenuated DA-induced inhibition without a significant effect on basal firing rate. At higher concentrations ( $>10 \mathrm{nM}$ ), it increased cell firing. At even higher concentrations $(>100$ $\mathrm{nM})$, NT abolished cell activity. The concentration of NT $(1 \mu \mathrm{M})$ used in the measurement of phospholipid turnover was very high (Geodert et al., 1984). It is therefore possible that the increase in the hydrolysis of inositol phospholipids induced by NT and subsequent activation of protein kinase $\mathrm{C}$ may be responsible for the action of NT at high concentrations. Consistent with this suggestion, PDBu, in the present study, also inhibited DA cell firing. However, further studies are needed to determine if the cessation of cell firing induced by NT is truly mediated by an activation of protein kinase $C$.

In summary, our results suggest that DA-induced inhibition of DA cell activity is unlikely due to the inhibition of adenylate cyclase, since compounds (SQ22536 and H8) that inhibit either adenylate cyclase or protein kinase A did not mimic the inhibitory effect of DA on the activity of DA cells, and 8-bromocAMP acting beyond the step of adenylate cyclase only attenuated this effect of DA. On the other hand, our results support the notion that intracellular cAMP and protein kinase A have an important regulatory role in the effect of DA. Activation of adenylate cyclase or protein kinase $\mathrm{A}$ by forskolin and 8-bromocAMP, respectively, significantly attenuated DA-induced inhibition of DA cells. Using specific inhibitors for the enzymes involved in the intracellular cAMP system, we also examined the possible involvement of cAMP in the modulatory effect of NT on DA cells. Our results suggest that NT may attenuate $\mathrm{D} \Lambda$-induced inhibition by increasing the activity of adenylate cyclase and protein kinase A. Inhibitions of these enzymes by SQ22536 and H8 effectively antagonized the effect of NT.

The activity of midbrain DA neurons appears to be controlled through a remarkable variety of different mechanisms including autoreceptors, cotransmitters, and feedback and nonfeedback pathways. Our results suggest that NT plays a part in these control mechanisms. Although adding yet one more complexily to DA system, NT's actions provide a control mechanism that could malfunction and thus be a part of the pathogenesis of diseases thought to be in part due to abnormal DA system functioning (e.g., movement disorders and schizophrenia). Conversely, if agonists and antagonists of NT receptors could be developed that cross the blood-brain barrier, we might have new drugs that would be useful in treating these same disorders.

\section{References}

Adachi DK, Kalivas PW, Schenk JO (1990) Neurotensin binding to dopamine. J Neurochem 54:1321-1328.

Agnati LF, Fuxe K, Benfenati F, Battistini N (1983) Neurotensin in vitro markedly reduces the affinity in subcortical limbic ${ }^{3} \mathrm{H}-N$-propylnorapomorphine binding sites. Acta Physiol Scand 119:459-461.

Anwer K, Hovington JA, Sanborn BM (1990) Involvement of protein kinase $A$ in the regulation of intracellular free calcium and phosphoinositide turnover in rat myometrium. Biol Reprod 43:851-859.

Bankey P, Carlson A, Ortiz M, Singh R, Cerra F (1990) Tumor necrosis 
factor production by Kupfer cells requires protein kinase $\mathrm{C}$ activation. J Surg Res 49:256-261.

Boulis N, Davis M (1990) Blockade of the spinal excitatory effect of cAMP on the startle reflex by intrathecal administration of the isoquinolinesulfonamide $\mathrm{H} 8$ : comparison to the protein kinase $\mathrm{C}$ inhibitor, H7. Brain Res 535:198-204.

Bunney BS, Walters JR, Roth RH, Aghajania GK (1973) Dopaminergic neurons: effect of antipsychotic drugs and amphetamine on single cell activity. J Pharmacol Exp Ther 185:560-571.

Conn PJ, Strong JA, Azhderian EM, Nairn AC, Greengard P, Kaczmarek LK (1989) Protein kinase inhibitors selectively block phorbol ester- or forskolin-induced changes in excitability of Aplysia neurons. J Neurosci 9:473-479.

Elazar Z, Fuchs S (1991) Phosphorylation by cyclic AMP-dependent protein kinase modulates agonist binding to the $\mathrm{D} 2$ dopamine receptor. J Neurochem 56:75-80.

Funase K (1990) Oxytocin-induced sodium current is mediated by cAMP-dependent protein phosphorylation in an identified snail neuron. Brain Res 517:263-268.

Goedert M, Pinnock RD, Downes CP, Mantyh PW, Emson PC (1984) Neurotensin stimulates inositol phospholipid hydrolysis in rat brain slices. Brain Res 323:193-197.

Grace AA, Bunney BS (1983) Intracellular and extracellular electrophysiology of nigral dopaminergic neurons $-\mathrm{I}$. Identification and characterization. Neuroscience 10:301-315.

Harris DN, Asaad MM, Phillips MB, Goldenberg HJ, Antonaccio MJ (1979) Inhibition of adenylate cyclase in human blood platelets by 9-substituted adenine derivatives. J Cyclic Nucleotide Res 5:125134.

Hidaka H, Inagaki M, Kawamoto S, Sasaki Y (1984) Isoquinolinesulfonamides, novel and potent inhibitors of cyclic nucleotide dependent protein kinase and protein kinase C. Biochemistry 23:50365041.

Innis RB, Aghajanian GK (1987) Pertussis toxin blocks autoreceptormediated inhibition of dopaminergic neurons in rat substantia nigra. Brain Res 411:139-143.

Kalivas P (1992) Sensitization of mesolimbic dopamine by neurotensin. Ann NY Acad Sci, in press.

Kanba KS, Kanba S, Okazaki H, Kichelson E (1986) Binding of $\left[{ }^{3} \mathrm{H}\right]-$ neurotensin in human brain: properties and distribution. J Neurochem 46:946-952.

Lacey MG, Mercuri NB, North RA (1987) Dopamine acts on $D_{2}$ receptors to increase potassium conductance in neurons of the rat substantia nigra zona compacta. J Physiol (Lond) 392:387-416.

Limbird LE (1988) Receptors linked to inhibition of adenylate cyclase: additional signaling mechanisms. FASEB J 2:2686-2695.

Linden DJ, Routtenberg A (1989) cis-Fatty acids, which activate protein kinase $\mathrm{C}$, attenuate $\mathrm{Na}^{+}$and $\mathrm{Ca}^{2+}$ currents in mouse neuroblastoma cells. J Physiol (Lond) 419:95-1 19.

Madison DV, Nicoll RA (1986) Cyclic adenosine 3',5'-monophosphate mediates receptor actions of noradrenaline in rat hippocampal pyramidal cells. J Physiol (Lond) 372:245-259.

Manejwala FM, Logan CY, Schultz RM (1991) Regulation of hsp70 mRNA levels during oocyte maturation and zygotic gene activation in the mouse. Dev Biol 144:301-308.

Memo M, Pizzi M, Nisoli E, Missale C, Carruba MO, Spano P (1987) Repeated administration of $(-)$ sulpiride and $\mathrm{SCH} 23390$ differentially up-regulate D- 1 and D-2 dopamine receptor function in rat mesostriatal areas but not in cortical-limbic brain regions. Eur J Pharmacol $138: 45-51$.
Mitsuhashi M, Payan DG (1988) Phorbol ester-mediated desensitization of histamine $\mathrm{H} 1$ receptors on cultured smooth muscle cell line. Life Sci 43:1433-1440.

Moraru II, Laky M, Stanescu T, Buzila L, Popescu LM (1990) Protein kinase C controls Fc gamma receptor-mediated endocytosis in human neutropils. FEBS Lett 274:93-95.

Morita Y, Takaishi T, Honda Z, Miyamoto T (1988) Role of protein kinase $C$ in histamine release from human basophils. Allergy 43:100 104.

Moyse E, Rostene W, Vial M, Leonard K, Mazella J, Kitabgi P, Vincent $J P$, Beaudet A (1987) Distribution of neurotensin binding sites in rat brain: a light microscopic radioautographic study using monoiodo

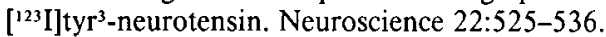

Nemeroff CB, Luttinger D, Hernandez DE, Mailman RB, Mason GA, Davis SD, Widerlov E, Frye GD, Kilts CD, Beaumont K, Breese GR, Prange AJ Jr (1983) Interactions of neurotensin with brain dopamine systems: biochemical and behavioral studies. J Pharmacol Exp Ther 225:337-345.

Poueymirou WT, Schultz RM (1989) Regulation of mouse preimplantation development: inhibition of synthesis of proteins in the two cell embryo that require transcription by inhibitors of cAMP-dependent protcin kinasc. Dev Biol 133:588-599.

Sarrieau A, Javoy-Agid F, Kitabgi P, Dussaillant M, Vail M, Vincent JP, Agid Y, Rostene WH (1985) Characterization and autoradiographic distribution of neurotensin binding sites in the human brain. Brain Res 348:375-380.

Shi W-X, Bunney BS (1988) 8-Bromo-cAMP mimics the effects of neurotensin in midbrain dopamine neurons: a study in brain slice. Soc Neurosci Abstr 14:78.

Shi W-X, Bunney BS (1989) Reversal of 8-bromo-cAMP- and neurotensin-induced attenuation of DA inhibition of DA neurons by a protein kinase A inhibitor, H8. Soc Neurosci Abstr 15:1322.

Shi W-X, Bunney BS (1990) A small volume chamber for electrical recording from submerged brain slice and a pulse-free medium supply system using a peristaltic pump. J Neurosci Methods 35:235-240.

Shi W-X, Bunney BS (1991a) Neurotensin modulate autoreceptor mediated dopamine effects on midbrain dopamine cell activity. Brain Res 543:315-321.

Shi W-X, Bunney BS (1991b) Effects of NT on midbrain dopamine neurons: are they mediated by formation of NT-DA complex? Synapse 9:79-94

Teitelbaum I (1990) Cyclic adenosine monophosphate and diacylglycerol: mutually inhibitory second messengers in cultured rat inner medullary collecting duct cells. J Clin Invest 86:46-51.

Tokimasa T, Akasu T (1990) Cyclic AMP regulates an inward rectifying sodium-potassium current in dissociated bull-frog sympathetic neurons. J Physiol (Lond) 420:409-429.

Von Euler G, Fuxe K (1987) Neurotensin reduces the affinity of D-2 dopamine receptors in rat striatal membranes. Acta Physiol Scand 131:625-626.

Watanabe K, Funase K (1991) Cyclic AMP elicits biphasic current whose activation is mediated through protein phosphorylation in snail neurons. Neurosci Res 10:64-70.

White FJ, Wang RY (1984) Pharmacological characterization of dopamine autoreceptors in rat ventral tegmental area: microiontophoretic studies. J Pharmacol Exp Ther 231:275-280.

Yomato E, Idegami H, Tahara $Y$, Cha T, Yoneda H, Noma Y, Shima $K$, Ogihara T (1990) Role of protein kinase $C$ in the regulation of glucagon gene expression by arginine. Biochem Biophys Res Commun 171:898-904. 